\title{
Police Personnel Affective Profiles: Differences in Perceptions of the Work Climate and Motivation
}

\author{
Ann-Christine Andersson Arntén • Nabeel Abd Algafoor • \\ Ali Al Nima • Erica Schütz • Trevor Archer • \\ Danilo Garcia
}

Published online: 25 February 2015

(C) The Author(s) 2015. This article is published with open access at Springerlink.com

\begin{abstract}
The affective profile model was used to investigate individual differences in police personnel perceptions about the working climate and its influences on motivation. The Positive Affect, Negative Affect Schedule (PANAS) was used to assign police personnel, sworn and non-sworn $(N=595)$, to four affective profiles: self-fulfilling, low affective, high affective, and self-destructive. The work climate was assessed using the Learning Climate Questionnaire (Management Relations and Style, Time, Autonomy and Responsibility, Team Style, Opportunities to Develop, Guidelines on How to do the Job, and Contentedness). Motivation was evaluated using a modified version (to refer specifically to the individual's work
\end{abstract}

A.-C. Andersson Arntén $(\bowtie)$

Office of the National Police Commissioner, National Police Board, P.O.Box 12256, SE - 10226 Stockholm, Sweden

e-mail: ann-christine.arnten@rps.police.se

A.-C. Andersson Arntén • A. Al Nima • E. Schütz • T. Archer •

D. Garcia

Network for Empowerment and Well-Being, Gothenburg, Sweden

N. A. Algafoor

Department of Psychology, University of Mustansiryah,

Bagdad, Iraq

E. Schütz $\cdot$ T. Archer

Department of Psychology, University of Gothenburg,

Gothenburg, Sweden

E. Schütz

Department of Psychology, Linnaeus University, Kalmar, Sweden

D. Garcia $(\bowtie)$

Institute of Neuroscience and Physiology, Centre for Ethics, Law and Mental Health (CELAM), University of Gothenburg, Wallinsgatan 8, SE 43141 Mölndal, Gothenburg, Sweden

e-mail: danilo.garcia@icloud.com

D. Garcia

e-mail: danilo.garcia@neuro.gu.se situation) of the Situational Motivation Scale (intrinsic motivation, external regulation, identified regulation, and amotivation). Self-fulfilling individuals scored higher on all work climate dimensions compared to the other three groups. Compared to low positive affect profiles, individuals with profiles of high positive affect scored higher in intrinsic motivation and identified regulation. Self-destructive individuals scored higher in amotivation. Different aspects of the work climate were related to each motivation dimension among affective profiles. Police personnel may react to their work environment depending on their affective profile. Moreover, the extent to which the work influences police personnel's motivation is also related to the affective profile of the individual.

Key words Affective Profiles · Learning Work Climate · Motivation · Police Personnel · Self-Determination Theory

\section{Introduction}

The work climate (i.e., employees' perceptions of how they are treated and managed in their organization) is important when organizations try to motivate employees to allocate and enhance their efforts in the workplace (Boudrias et al., 2010; Neal et al., 2005). The effectiveness of an organization in creating a climate in which employees are able to learn from each other and/or new experiences is crucial for the effectiveness of the development of the organization (Mikkelsen et al., 1998). In addition, different facets of the working climate (e.g., having good relations and trust in managers and colleagues, having autonomy in making decisions and allocated time for performing tasks, having opportunities to develop within the workplace, having clear and well-known guidelines on how to perform tasks, and having job satisfaction) 
influence personnel's experience of stress in the workplace (Mikkelsen et al., 1998; Zhao et al., 2002). It is also evident that these aspects of the working climate are important for different dimensions of motivation among personnel (Atkinson, 1964; Campbell \& Pritchard, 1976; Ryan \& Deci, 2000a; Vroom, 1964), which in turn, modulates stress at work (Archer et al., 2008a). Moreover, individual differences in affectivity, self-esteem and level of depressiveness and anxiety have been associated with the different dimensions of motivation (Archer et al., 2008a). As observed previously, affectivity is an important predictor of intrinsic motivation and work climate (cf. Andersson Arntén, 2009).

The present study used the affective profile model, which offers a uniqueness over and above the single dimensional framework of affectivity by taking into account how positive and negative affectivity interact, to investigate individual differences in perceptions about the working climate and its influences on motivation (for a review see Garcia et al., 2013). First, we outline the definition of motivation that will be used here. We then briefly outline previous research conducted using the affective profile model.

\section{Motivation: Intrinsic Motivation, Extrinsic Motivation} (External and Identified Regulation), and Amotivation

The term "motivation" originates from the Latin word movere, which implies movement (Steers et al., 2004). Hence, researchers often describe motivation as 'being moved to do something' (Atkinson, 1964; Campbell \& Pritchard, 1976; Ryan \& Deci, 2000a; Vroom, 1964). Nevertheless, many motivation theories are concerned either about external or internal processes (Katzell \& Thompson, 1990). While theories that emphasize external processes try to demonstrate pragmatic levers for improving motivation and performance, theories that emphasize internal processes explain cognitive mechanisms that make people behave in a specific way in the workplace (Katzell \& Thompson, 1990). The Self-Determination Theory (Deci \& Ryan, 1985; Ryan \& Deci, 2000b) concept of motivation concentrates on three fundamental psychological needs (cf. Archer et al., 2008a): competence, autonomy and relatedness. These three elements are the distinguishing factors between different motivation dimensions based on the different reasons or goals that promote certain actions (Ryan \& Deci, 2000a, 2000b).

In the framework of Self-Determination Theory, Guay and colleagues (2000) imply that "situational (or state) motivation, as measured at a given point in time, provides a useful understanding of a person's current (or state) self-regulatory processes" (p. 176). Therefore, they presented the Situational Motivation Scale, a scale that presents a notion of motivation as being composed of four dimensions: intrinsic motivation, internal regulation, external regulation and amotivation. Intrinsic motivation refers to the involvement in an activity because performing it brings about pleasure and satisfaction. Intrinsically motivated individuals participate in an activity voluntarily, without expecting rewards and without need for external or internal pressures or regulations to make them do so (Deci \& Ryan, 1985). Extrinsic motivation is defined as engagement in an activity in order to achieve some sort of reward, because of external or internal pressures, or to fulfill any kind of regulation (Deci \& Ryan, 1985). Extrinsic motivation is, in the situational concept (Guay et al., 2000), measured and composed of two dimensions: (a) external regulation refers to involvement in an activity to gain rewards or to avoid punishment, and (b) identified regulation, which denotes a more "internalized" engagement that is not yet selfdetermined, but it is a starting point for the individual to internalize the reasons for her/his activity. Finally, amotivation refers to the absence of contingency between one's actions and their outcomes (Barkoukis et al., 2008). Specifically, amotivation expresses the lack of specific purposes and goals, and the inability to indicate the intent to engage in an activity. Individuals' amotivation may originate from their learned helplessness, which respectively makes them avoid effort; they perceive themselves as incompetent and without control, and as persons who are involved in activities against their will (Deci \& Ryan, 1985).

\section{The Affective Profiles}

Affect is suggested to be composed of two systems, positive affect (PA) and negative affect (NA), which reflect relatively stable cognitive emotional profiles as dispositions or signal sensitivity systems (e.g., Tellegen, 1985, 1993; Watson \& Clark, 1994). The notion of affectivity presents a confluence of emotions and attributes - psychological, biological and social - that determine individuals' perceptions and experiences of situations (Cloninger \& Garcia, in press). The Positive Affect and Negative Affect Schedule (PANAS; Watson, Clark, \& Tellegen, 1988) is one of the most commonly used instruments to measure affect and was developed on the premise that PA and NA represent two orthogonal independent dimensions: high PA versus low PA and high NA versus low NA (see Watson \& Tellegen, 1985). The conceptualization of each affect dimension categorized as high and low, leads to four different combinations beyond the two-system approach (Garcia, 2011). According to this notion, Archer and colleagues have modified and developed the affective profiles model through self-reported affectivity measured by the PANAS, generating four different profiles: self-fulfilling (high PA, low NA, ) high affective (high PA, high NA); low affective (low PA, low NA); and self-destructive (low PA, high NA) (e.g., Archer et al., 2007; Bood et al., 2004; Norlander et al., 2002; Norlander et al., 2005a). The construction of the four affective categories extends the affectivity notion to more 
than two separate systems by taking into account the interaction of both dispositions (PA and NA).

Self-fulfilling individuals report feeling more energetic and optimistic than the other three affective profiles (Archer et al., 2007), while both self-fulfilling and high affective profiles, compared to low affective and self-destructive profiles, perform better during stressful situations (e.g., Norlander et al., 2002), have a more active life, i.e., exercise more often and more intensively (Archer, 2014; Garcia and Archer, 2014), and have better coping strategies (Andersson Arntén et al., 2008). Even differences in physiological measures have been discerned; such as high PA profiles (i.e., self-fulfilling and high affective) having lower blood pressure (Norlander et al., 2002, 2005a). Garcia (2011) explained these findings by referring to theories suggesting that PA, specifically as measured by the PANAS, helps make individuals more resilient, more receptive for positive cues in the environment, and more likely to display approaching behavior (e.g., Cloninger, 2004, 2006; Fredrickson, 2006; Higgins, 1997). Tugade and Fredrickson (2004), for example, showed that high PA individuals, compared to low PA individuals, recovered their normal cardiovascular activation more quickly following a stressful task.

In contrast, Kunst (2011) showed that high affective and self-destructive profiles were strongly associated with increased posttraumatic stress disorder symptom severity. Also in this vein, Garcia (2012) showed that high affective and selfdestructive profiles, compared to self-fulfilling and low affective individuals, scored higher on Neuroticism. This could perhaps explain the association between high affective and self-destructive profiles to increased posttraumatic stress disorder symptoms severity (Kunst, 2011) and reports on these profiles to have more stressful experiences in their lives (Norlander et al., 2005a). Moreover, while low affective profiles show maladaptive responses to induced stress, compared to self-fulfilling and high affective individuals (Norlander et al., 2002), they also experience less stress in their lives (Norlander et al., 2005a). With regard to police officers, high PA profiles have been linked not only to the ability to recover from a traumatic event, but also improved levels of functioning (Norlander et al., 2005b). Finally, gender differences in affectivity have been discerned, with females expressing higher affectivity compared to males (Karlsson \& Archer, 2007).

\section{The Present Study}

The aim of the present study was to investigate differences in self-reported perceptions of the work climate among police personnel. The affective profile model was used to investigate how work climate may be related to individuals' expressions of motivation.

\section{Method}

Participants and Procedure

The present study was based on a sample of 617 participants (males $=318$, females $=292$, and 7 participants who didn't report their gender). These 617 participants held different job positions: 212 police officers, 104 police leaders, 185 police investigators, 96 non sworn personnel, and 20 who did not report their job position. The participants were recruited from five different police districts around Sweden (Police district 1 $n=101$; Police district $2 n=119$; Police district $3 n=230$; Police district $4 n=98$; Police district $5 n=62$; missing data $=$ seven that did not specify what district they worked in). The Police districts were chosen in order to obtain a geographic overview of the country and to represent both large cities and smaller communities. The response rate was between 65 and 85 percent with the exception of one district where the rate was 17.7 percent giving an overall response rate average at 62.96 percent.

The selected police district invited all their employees to participate in the study and were informed by their respective managers that participation was voluntary, anonymous and could be carried out during working hours. The tests were distributed in paper form in an envelope in four out of five districts, but were distributed on-line in one of the districts. This district was the district with the low response rate of 17.7 $\%$, which indicates that the form of distribution might have an impact on response rate. This is a common phenomenon of on-line-distributed as opposed to paper-and-pencil-distributed questionnaires (Shih \& Fan, 2008).

\section{Instruments}

Positive Affect and Negative Affect Schedule (PANAS; Watson et al., 1988) The PANAS instructs participants to rate to what extent they generally have experienced 20 different feelings or emotions (10 PA and $10 \mathrm{NA}$ ) during the last week, using a 5point Likert scale $(1=$ very slightly, $5=$ extremely $)$. The 10 item PA scale includes adjectives such as strong, proud, and interested. The 10-item NA scale includes adjectives such as afraid, ashamed, and nervous. In their study, Lindahl and Archer (2013) reported a Cronbach's alpha of .88 for the PA scale and .83 for the NA scale.

The Learning Climate Questionnaire (Bartram et al., 1993) This instrument comprises 70 items with a 5-point Likert scale for each item $(1=$ extremely disagree, $5=$ extremely agree $)$, and is organized in seven subscales that provide means for looking at the working climate in more detail: Management Relations and Style (e.g., "My immediate manager makes me feel like a valuable member of the team"), Time (e.g., "I have time to do my job properly"), Autonomy and Responsibility 
(e.g., "I feel free to organize my work the way I want to"), Team Style (e.g., "If we ask each other for help it is given"), Opportunities to Develop (e.g., "There are lots of different ways to learn new jobs here"), Guidelines on How to Do the Job (e.g., "Information relevant to my job is kept up-to-date"), and Contentedness (e.g., "People tend to put each other down"). In a recent study, Garcia and Archer (2012) reported the following Cronbach's alphas as measures of reliability: Management Relations and Style .87; Time .90; Autonomy and Responsibility .81; Team Style .77; Opportunities to Develop .80; Guidelines on How to Do the Job .73; Contentedness .81 (for similar reliability coefficients see also Garcia, Rapp Ricciardi, \& Archer, 2015).

Situational Motivation Scale (Guay et al., 2000) For the present study, the Situational Motivation Scale was modified by altering the questions to refer to individuals' work and/or activities. The instrument measures four motivation dimensions: Intrinsic Motivation (e.g., "Because I think my work is interesting"), External Regulation (e.g., "Because I am supposed to do it"), Identified Regulation (e.g., "Because I am doing it for my own good"), and Amotivation (e.g., "I do this work but I am not sure it is worth it"). Each item is answered using a 7-point Likert scale $(1=$ extremely disagree, $7=$ extremely agree). In their study, Lindahl and Archer (2013) reported the following Cronbach's alphas for reliability: Intrinsic Motivation .85, Identified Regulation .71, External Regulation .77, Amotivation .86.

\section{Statistical Treatment}

Self-reported levels of affect measured by the PANAS were used to classify participants in the four affective profiles. Participants' PA and NA scores were divided into high and low categories (i.e., median split); the combination of this categorization yielded the four affective profiles (see Norlander et al., 2002). The cut-off points in the present study were: low $\mathrm{PA}=3.6$ or less, high $\mathrm{PA}=3.7$ or more, low $\mathrm{NA}=1.5$ or less, and high NA $=1.6$ or more.

The two independent variables of the study were gender and affective profile: self-fulfilling ( $n=143 ; 73$ males, 70 females), high affective ( $n=144 ; 62$ males, 82 females), low affective ( $n=138 ; 82$ males, 56 females), and selfdestructive ( $n=170 ; 96$ males, 74 females). The seven dimensions of work climate and the four dimensions of situational motivation were considered as dependant variables. We analyzed our data using a Multiple Analysis of Variance (MANOVA) instead of multiple ANOVAS because the MANOVA also determines the interactions taking place amongst dependent variables (Tabachnick \& Fidell, 2007).

The Expectation-Maximization Algorithm (EMAlgorithm) was used to deal with missing values (less than
$5 \%$ in all cases). Little's Chi-Square test for Missing Completely at Random was, $\chi 2(112, n=595)=95.58, p=$ .91. This means that the missing data was missing at random and not systematically; thus, the EM-Algorithm is appropriate for replacing the missing data (Tabachnick \& Fidell, 2007). Based on the EM-Algorithm, 595 participants' responses ( males $=313$, females $=282$ ) were found to be valid.

Next, we detail the analysis used for data cleaning and assessment of statistical assumptions for the use of the MANOVA and Regression Analysis used in the present study (see Tabachnick \& Fidell, 2007).

\section{Evaluation of Assumptions for MANOVA}

\section{Normality of Sampling Distributions}

Our sample size of 595 participants includes over 20 cases for each cell. Therefore, the normal sampling distributions of means for MANOVA was assumed (see Tabachnick \& Fidell, 2007, who point out that the Central Limit Theorem reassures us that, with sufficiently large sample sizes, sampling distributions of means are normally distributed regardless of the distributions of variables).

\section{Univariate Outliers}

To reduce the impact of variables with univariate outliers within each of the 8 cells/groups (i.e., 4 affective profiles $\times$ 2 genders), we first standardized the scores of each variable and tested if any cases had larger standardized scores than \pm 3.29 , as recommended by Tabachnick and Fidell (2007). The analysis detected five cases of univariate outliers in the amotivation variable, four cases in the intrinsic motivation, one case in identified regulation, two cases in team style, and one case in contentedness. After the square root transformation for amotivation, the analysis did not indicate any case as univariate outlier in this variable. The transformation reduced the skewness for amotivation for the whole sample from 1.34 to 0.08 and kurtosis from 1.70 to -.82 .

However, all common data transformations failed to remove the outliers with regard to intrinsic motivation, identified regulation, team style, and contentedness. These outliers were therefore replaced with suitable values for each variable's attribute. Specifically, outliers were changed to the next highest/lowest (non-outlier) number or to the next highest/ lowest (non-outlier) number $+1 /-1$ (see Tabachnick \& Fidell, 2007). After the transformation and replacement, all the impacts of variables with univariate outliers via groups were reduced and the variables were normally distributed for all variables, except intrinsic motivation: skewness between -.89 to -.01 , kurtosis between -.82 to .09 . The replacement reduced the skewness for intrinsic motivation from -1.16 to 1.12 and kurtosis from 1.12 to .90 . Nevertheless, our sample 
size was relativity large $(N=595)$; thus, these values are reasonable (see Tabachnick \& Fidell, 2007).

\section{Multivariate Outliers}

Multivariate outliers were investigated for the learning climate dimensions (for the first MANOVA) via 8 cells/groups (4 affective profiles $\times 2$ genders). The result showed, with seven variables, a criterion $\alpha=.001$, and a critical $x^{2}=24.32$, that just one value could be considered as a multivariate outlier (in the self-destructive-female cell). This was replaced with a suitable value.

Multivariate outliers were also investigated for the motivation dimensions (for the second MANOVA) via 8 cells/groups ( 4 affective profiles $\times 2$ genders). The result showed, with four variables, a criterion $\alpha=.001$, and a critical $x^{2}=18.47$, that two values could be considered as multivariate outliers (the first value in the self-destructive-male cell and the second value in the self-fulfilling-female cell). These values were replaced with suitable values (see Tabachnick \& Fidell, 2007).

\section{Homogeneity of Variance-covariance Matrices}

Results showed that Box's M test was significant at $p<.001$ for both the first and second MANOVA. Nevertheless, several reasons suggest no need to be concerned that the assumptions of homogeneity of variance and covariance matrices were violated (see Tabachnick \& Fidell, 2007): the groups sample sizes were large, there were very small differences between group sample sizes, groups with larger sizes produced larger variances and covariances than the groups with smaller sizes, and there were only small differences in the groups sizes of the variances and co-variances matrices.

\section{Linearity}

The linearity for all learning climate dimensions (first MANOVA) and for all motivation dimensions (second MANOVA) in each group was examined by scatter plots for each pair, respectively. The results showed no problem with linearity and indicated that these variables had reasonably balanced distributions.

\section{Multi-colinearity and Singularity}

All the correlations among learning climate dimensions by affective profiles, and all the correlations among motivation dimensions by affective profiles, were expected to be high, but not so high as to threaten statistical multicollinearity and singularity. These correlation coefficients are all below .71; thus, we considered multicollinearity not to be a problem (see Tabachnick \& Fidell, 2007).
Evaluation of Assumptions for Regression Analysis

Ratio of Cases to Independent Variables

According to Tabachnick and Fidell (2007) simple rules of thumb are $50+8 \mathrm{~m} \leq \mathrm{N}$ (where $\mathrm{m}$ is the number of independent variables) for testing the multiple correlation and $104+\mathrm{m}$ $\leq \mathrm{N}$ for testing individual predictors. Our analysis was based on a relatively large sample $(N=595)$ with as many as 138 cases in the smallest cell (i.e., self-destructive) and seven independent variables. Therefore, the number of cases was above the minimum requirement of $111(104+7)$ for testing individual predictors in standard multiple regressions.

\section{Normality, Linearity and Homoscedasticity}

We examined the distributions of the variables (learning climate and motivation dimensions) by affective profiles using scatter plots. We also tested the predictors (i.e., the learning climate dimensions) in a standard multiple regression to produce the scatter plots of residuals against the dependent variables (i.e., the motivation dimensions) to further examine normality, linearity, and homoscedasticity (see Tabachnick \& Fidell, 2007). The results showed that the variables had reasonably balanced distributions and that there were no threats to normality, linearity or homoscedasticity.

\section{Results}

Table 1 presents the correlations, means, standard deviations, and Cronbach's alphas for all the variables in the study.

\section{Differences in Learning Climate Dimensions}

A Multiple Analysis of Variance (MANOVA) indicated a significant effect for affective profile $(F(21,1749)=11.28 ; p<$ .001 , Partial $\eta^{2}=.12$, Wilks' Lambda $\left.=.68\right)$. The effect of gender was not significant $(F(7,581)=1.42 ; p=.193$, Partial $\eta^{2}=.02$, Wilks' Lambda $\left.=.98\right)$, nor was the interaction of affective profile and gender $(F(21,1749)=1.39 ; p=.111$, Partial $\eta^{2}=.02$, Wilks' Lambda $\left.=.95\right)$. A between-subjects ANOVA showed significant effects of affective profiles on all learning climate dimensions: Management Relations and Style $(F(3,587)=26.17 ; p<.001)$, Time $(F(3,587)=$ $33.24 ; p<.001)$, Autonomy and Responsibility $(F(3,587)=$ $35.74 ; p<.001)$, Team Style $(F(3,587)=28.16 ; p<.001)$, Opportunities to Develop $(F(3,587)=44.18 ; p<.001)$, Guidelines on How to Do the $\operatorname{Job}(F(3,587)=37.44 ; p<$ $.001)$, and Contentedness $(F(3,587)=21.03 ; p<0.001)$.

Bonferroni testing was conducted to compare the mean differences in the seven learning climate dimensions between affective profiles. The results, as expected, showed that self- 
Table 1 Correlations, means, standard deviations, and Cronbach's alphas for all variables in Study $1(\mathrm{~N}=595)$.

\begin{tabular}{|c|c|c|c|c|c|c|c|c|c|c|c|c|c|}
\hline & 1 & 2 & 3 & 4 & 5 & 6 & 7 & 8 & 9 & 10 & 11 & 12 & 13 \\
\hline (1) Positive Affect & - & & & & & & & & & & & & \\
\hline (2) Negative Affect & -.06 & - & & & & & & & & & & & \\
\hline (3) Management Relations and Style & $.31^{* *}$ & $-.26^{* *}$ & - & & & & & & & & & & \\
\hline (4) Time & $.16^{* *}$ & $-.40^{* *}$ & $.25^{* *}$ & - & & & & & & & & & \\
\hline (5) Autonomy and Responsibility & $.25^{* *}$ & $-.40^{* *}$ & $.41^{* *}$ & $.51^{* *}$ & - & & & & & & & & \\
\hline (6)Team Style & $.23^{* *}$ & $-.34^{* *}$ & $.53^{* *}$ & $.38^{* *}$ & $.39^{* *}$ & - & & & & & & & \\
\hline (7) Opportunities to Develop & $.40^{* *}$ & $-.37^{* *}$ & $.51^{* *}$ & $.45^{* *}$ & $.64^{* *}$ & $.48^{* *}$ & - & & & & & & \\
\hline (8) Guidelines on How to do the Job & $.27^{* *}$ & $-.39^{* *}$ & $.44^{* *}$ & $.56^{* *}$ & $.44^{* *}$ & $.58^{* *}$ & $.66^{* *}$ & - & & & & & \\
\hline (9) Contentedness & .04 & $-.34^{* *}$ & $.28^{* *}$ & $.44^{* *}$ & $.36^{* *}$ & $.47^{* *}$ & $.37^{* *}$ & $.42^{* *}$ & - & & & & \\
\hline (10) Intrinsic Motivation & $.59^{* *}$ & $-.17^{* *}$ & $.32^{* *}$ & $.17^{* *}$ & $.28^{* *}$ & $.29^{* *}$ & $.40^{* *}$ & $.34^{* *}$ & .05 & - & & & \\
\hline (11) Identified Regulation & $.42^{* *}$ & $-.10^{*}$ & $.20^{* *}$ & $.10^{*}$ & $.20^{* *}$ & $.20^{* *}$ & $.36^{* *}$ & $.26^{* *}$ & .05 & $.64^{* *}$ & - & & \\
\hline (12) External Regulation & $-.15^{* *}$ & $.15^{* *}$ & $-.19^{* *}$ & -.07 & $-.17^{* *}$ & $-.16^{* *}$ & $-.18^{* *}$ & $-.11^{* *}$ & -.05 & $-.30^{* *}$ & .01 & - & \\
\hline (13) Amotivation & $-.30^{* *}$ & $.39^{* *}$ & $-.26^{* *}$ & $-.32^{* *}$ & $-.41^{* *}$ & $-.25^{* *}$ & $-.45^{* *}$ & $-.36^{* *}$ & $-.19^{* *}$ & $-.51^{* *}$ & $-.32^{* *}$ & $.34^{* *}$ & - \\
\hline Mean & 3.52 & 1.69 & 3.78 & 2.81 & 3.59 & 3.85 & 3.08 & 3.28 & 2.41 & 22.06 & 18.64 & 12.71 & 8.10 \\
\hline Std. Deviation & 0.71 & 0.52 & 0.80 & 0.69 & 0.55 & 0.58 & 0.60 & 0.58 & 0.64 & 4.64 & 4.85 & 5.52 & 4.27 \\
\hline Cronbach's $\alpha$ & .89 & .80 & .91 & .84 & .74 & .82 & .77 & .75 & .80 & .89 & .66 & .75 & .72 \\
\hline
\end{tabular}

Note: $* p<.05, * * p<.01$.

fulfilling individuals scored significantly higher in all learning climate dimensions compared to the other three affective profiles. However, one exception to this finding was the Time dimension of the learning climate. While self-fulfilling individuals scored significantly higher than both high affective and self-destructive individuals in the Time dimension, selffulfilling individuals did not score significantly higher than low affective individuals, who in turn scored significantly higher than both high affective and self-destructive in this dimension. Low affective individuals also scored significantly higher in the Contentedness dimension compared to high affective and self-destructive individuals. See Table 2 for means and standard deviations of each of the seven learning climate dimensions among the four affective profiles.

\section{Differences in Motivation Dimensions}

MANOVA indicated a significant effect for affective profile $\left(F(12,1545.41)=16.79 ; p<.001\right.$, Partial $\eta^{2}=.10$, Wilks' Lambda $=.72)$. The effect of gender was not significant $(F(4$, $584)=1.39 ; p=.236$, Partial $\eta^{2}=.01$, Wilks' Lambda $\left.=.99\right)$, nor was the interaction of affective profile and gender $(F(12$, $1545.41)=0.84 ; p=.613$, Partial $\eta^{2}=.01$, Wilks' Lambda $=$ 98). A between-subjects ANOVA showed significant effects for affective profiles on all motivation dimensions: intrinsic motivation $(F(3,587)=50.74 ; p<.001)$, identified regulation $(F(3,587)=22.32 ; p<.001)$, external regulation $(F(3,587)=$ $2.83 ; p<.05)$, and amotivation $(F(3,587)=31.73 ; p<.001)$.

A Bonferroni test was conducted to compare the mean differences in the four motivation dimensions between affective profiles. The results showed that profiles with high PA (i.e., self-fulfilling and high affective) scored significantly higher in intrinsic motivation and identified regulation than profiles with low PA (i.e., low affective and self-destructive). The self-destructive individuals, however, scored significantly higher in amotivation compared to all the other affective profiles. See Table 2 for means and standard deviations of each of the four motivation dimensions among the four affective profiles.

\section{Learning Climate in the Prediction of Motivation} among Affective Profiles

We conducted multiple regression analyses to investigate which learning work climate dimensions predicted the four motivation dimensions for each affective profile. The results showed that Team Style and Opportunities to Develop predicted both intrinsic motivation and identified regulation among self-fulfillers. These results imply that cooperation and competence development in the work place might influence selffulfillers' 'inner-motivation' (it is possible that the reverse may be true also - that self-fulfillers inner motivation may influence cooperation and competence development, yet for reasons discussed below it seems likely that these work climate variables influence inner motivation)Autonomy and Responsibility counter-predicted identified regulation among these individuals, suggesting that greater Autonomy perceived by self-fulfillers was linked with less identified regulation. For those individuals expressing a high affective profile, Autonomy and Responsibility predicted intrinsic motivation and counter-predicted amotivation, while Contentedness counterpredicted identified regulation. Eventual links between sense 
Table 2 Means and standard deviations $( \pm)$ for all dependent variables organized in affective profile.

\begin{tabular}{lllll}
\hline Affective Profile & Self-fulfilling $(n=143)$ & High Affective $(n=144)$ & Low Affective $(n=138)$ & Self-destructive $(n=170)$ \\
\hline Management Relations and Style & $4.17 \pm 0.58^{\mathrm{H}, \mathrm{L}, \mathrm{D}}$ & $3.86 \pm 0.77^{\mathrm{D}}$ & $3.67 \pm 0.78^{\mathrm{D}}$ & $3.44 \pm 0.85$ \\
Time & $3.13 \pm 0.68^{\mathrm{H}, \mathrm{D}}$ & $2.66 \pm 0.63$ & $3.01 \pm 0.59^{\mathrm{H}, \mathrm{D}}$ & $2.49 \pm 0.64$ \\
Autonomy and Responsibility & $3.88 \pm 0.43^{\mathrm{H}, \mathrm{L}, \mathrm{D}}$ & $3.53 \pm 0.59^{\mathrm{D}}$ & $3.69 \pm 0.43^{\mathrm{D}}$ & $3.31 \pm 0.56$ \\
Team Style & $4.14 \pm 0.51^{\mathrm{H}, \mathrm{L}, \mathrm{D}}$ & $3.81 \pm 0.59^{\mathrm{D}}$ & $3.91 \pm 0.45^{\mathrm{D}}$ & $3.59 \pm 0.59$ \\
Opportunities to Develop & $3.43 \pm 0.52^{\mathrm{H}, \mathrm{L}, \mathrm{D}}$ & $3.14 \pm 0.55^{\mathrm{D}}$ & $3.09 \pm 0.49^{\mathrm{D}}$ & $2.73 \pm 0.59$ \\
Guidelines on How to do the Job & $3.63 \pm 0.57^{\mathrm{H}, \mathrm{L}, \mathrm{D}}$ & $3.22 \pm 0.57^{\mathrm{D}}$ & $3.33 \pm 0.46^{\mathrm{D}}$ & $2.99 \pm 0.53$ \\
Contentedness & $2.68 \pm 0.73^{\mathrm{H}, \mathrm{D}}$ & $2.23 \pm 0.61$ & $2.54 \pm 0.52^{\mathrm{H}, \mathrm{D}}$ & $2.22 \pm 0.55$ \\
Intrinsic Motivation & $24.43 \pm 2.98^{\mathrm{L}, \mathrm{D}}$ & $23.99 \pm 3.55^{\mathrm{L}, \mathrm{D}}$ & $20.56 \pm 4.72$ & $19.76 \pm 4.90$ \\
Identified Regulation & $20.43 \pm 4.56^{\mathrm{L}, \mathrm{D}}$ & $20.05 \pm 4.53^{\mathrm{L}, \mathrm{D}}$ & $17.53 \pm 4.78$ & $16.90 \pm 4.55$ \\
External Regulation & $11.62 \pm 5.72$ & $12.86 \pm 4.88$ & $13.23 \pm 5.70$ & $13.25 \pm 5.62^{\mathrm{S}}$ \\
Amotivation & $6.04 \pm 2.81$ & $7.98 \pm 3.98^{\mathrm{S}}$ & $7.64 \pm 3.52^{\mathrm{S}}$ & $10.31 \pm 5.04^{\mathrm{S}, \mathrm{H}, \mathrm{L}}$ \\
\hline
\end{tabular}

Note: Bonferroni test $\mathrm{p}<.001,{ }^{\mathrm{S}}=$ higher than Self-fulfilling, ${ }^{\mathrm{H}}=$ higher than High Affectives, ${ }^{\mathrm{L}}=$ higher than Low Affectives, ${ }^{\mathrm{D}}=$ higher than Selfdestructives

of autonomy and intrinsic motivation ought to imply necessity for further investigation. For the low affective individuals, Opportunities to Develop, Management Relations, and Style predicted intrinsic motivation and counter-predicted external regulation. However, at least for these latter individuals, possession of Guidelines on How to do the Job may have affected both dimensions of external motivation: identified and external regulation. External regulation was also predicted by Contentedness for low affective individuals. Team Style predicted intrinsic motivation among self-destructive individuals. Contentedness, however, was negatively related to intrinsic motivation for this profile. Finally, Opportunities to Develop predicted identified regulation and together with Autonomy and Responsibility counter-predicted amotivation (see Table 3 for the details).

\section{Discussion}

Previous studies concerning police personnel from different countries have shown that employees who are serving among law enforcement agencies show various types of personality profiles (Du Preez et al., 2009, 2011; Garbarino et al., 2013a,b). Although the investigation of personality traits/ profiles remains commonplace within studies of personnel groups, the focus upon affective profiles seems to have been neglected in common surveys. Studies on 'affectivity' generally present positive and negative affect as separate factors rather than the consideration of interactive dimensions that facilitate the categorization of individuals in affective profiles.

The present model ensures an examination of those attributes associated specifically with groups of individuals expressing different types of affect based on self-reported affect, thereby extending the applicability of the individual self-assessments. These results showed that (1) the affective profiles differed in their perception of the learning climate, (2) the affective profiles differed in the four motivation dimensions measured here, and that (3) different aspects of the learning climate predicted different dimensions of motivation among affective profiles in police personnel.

More specifically, the affective profile differences in the perception of the learning climate were expressed as follows: the self-fulfilling individuals scored significantly higher in all learning climate dimensions, except for the Time dimension, where they scored higher than the high affective and selfdestructive individuals, but not the low affective individuals. This observation implies that the self-fulfilling individuals perceived the work climate as a more learning-oriented climate than the three other groups of affective profiles (high affective, low affective, self-destructive). It is possible that the self-fulfilling individuals' optimistic outlook (Archer et al., 2007, 2008a), their expressions of more effective coping strategies (Andersson Arntén et al., 2008), and their reliance upon an internal locus of control (Archer et al., 2008b) allows them to regard alternative environments more positively than the other three affective profile groups. Nevertheless, among the self-fulfilling profile, autonomy and responsibility were negatively related to identified regulation, which may appear to be counter-intuitive; however, two considerations should be noted: (1) the observation may be situation-dependent, and (2) identified regulation does bear some degree of extraneous influence (Archer et al., 2008a; Weman-Josefsson, unpublished Master's dissertation, 2014). Further, both selffulfilling and low affective profiles are defined by low levels of NA. Thus, the observation that Opportunities to Develop related to intrinsic motivation for both these profiles ought to provide insight regarding the advantages of low negative affect.

The present findings showed also that the self-destructive group scored significantly lower on every dimension of the 
Table 3 Results of the regression analyses for each affective profile using the seven learning climate dimensions as predictors and the four motivation dimensions as outcome variables. Only showing significant predictors

\begin{tabular}{|c|c|c|c|c|c|c|c|c|}
\hline Predictor Variable & Outcome Variable & Adj $R^{2}$ & Unst. B & Unst. SE & Stand. $\beta$ & $F$ & $t$ & $p$ \\
\hline \multicolumn{9}{|l|}{$\underline{\text { Self-fulfilling }}$} \\
\hline Team Style & Intrinsic Motivation & - & 1.17 & .56 & .22 & - & 2.10 & $<.05$ \\
\hline \multirow[t]{2}{*}{ Opportunities to Develop } & & - & 1.63 & .72 & .31 & - & 2.28 & $<.05$ \\
\hline & & .11 & - & - & - & 3.93 & - & $<.001$ \\
\hline Autonomy and Responsibility & Identified Regulation & - & -2.69 & 1.11 & -.15 & - & -2.42 & $<.05$ \\
\hline Team Style & & - & 2.05 & .93 & .24 & - & 2.20 & $<.05$ \\
\hline \multirow[t]{2}{*}{ Opportunities to Develop } & & - & 2.54 & 1.20 & .30 & - & 2.12 & $<.05$ \\
\hline & & .07 & - & - & - & 2.47 & - & $<.05$ \\
\hline \multicolumn{9}{|l|}{ High Affective } \\
\hline Management Relations and Style & Intrinsic Motivation & - & 0.94 & .41 & .23 & - & 2.28 & $<.05$ \\
\hline \multirow[t]{2}{*}{ Autonomy and Responsibility } & & - & 1.26 & .57 & .23 & - & 2.21 & $<.05$ \\
\hline & & .15 & - & - & - & 4.56 & - & $<.001$ \\
\hline Contentedness & Identified Regulation & .10 & -1.59 & .71 & -.22 & 3.27 & -2.24 & $<.05$ \\
\hline Autonomy and Responsibility & Amotivation & .23 & -2.01 & .65 & -.31 & 7.20 & -3.10 & $<.001$ \\
\hline \multicolumn{9}{|l|}{$\underline{\text { Low Affective }}$} \\
\hline Opportunities to Develop & Intrinsic Motivation & .16 & 2.97 & 1.03 & .31 & 4.68 & 2.88 & $<.001$ \\
\hline Guidelines on How to do the Job & Identified Regulation & .06 & 2.66 & 1.27 & .26 & 2.34 & 2.09 & $<.05$ \\
\hline Management Relations and Style & External Regulation & - & -1.91 & .67 & -.26 & - & -2.84 & $<.01$ \\
\hline Opportunities to Develop & & - & -3.93 & 1.25 & -.34 & - & -3.15 & $<.01$ \\
\hline Guidelines on How to do the Job & & - & 3.37 & 1.44 & .27 & - & 2.33 & $<.05$ \\
\hline \multirow[t]{2}{*}{ Contentedness } & & - & 2.33 & 1.00 & .21 & - & 2.33 & $<.05$ \\
\hline & & .15 & - & - & - & 4.48 & - & $<.001$ \\
\hline \multicolumn{9}{|l|}{ Self-destructive } \\
\hline Team Style & Intrinsic Motivation & - & 1.95 & .77 & .24 & - & 2.52 & $<.01$ \\
\hline \multirow[t]{2}{*}{ Contentedness } & & - & -2.00 & .79 & -.22 & - & -2.53 & $<.01$ \\
\hline & & .11 & - & - & - & 3.93 & - & $<.001$ \\
\hline Opportunities to Develop & Identified Regulation & .13 & 3.06 & .80 & .40 & 4.67 & 3.81 & $<.001$ \\
\hline Autonomy and Responsibility & Amotivation & - & -1.98 & .82 & -.22 & -2.41 & - & $<.01$ \\
\hline \multirow[t]{2}{*}{ Opportunities to Develop } & & - & -2.39 & .87 & -.28 & - & -2.76 & $<.01$ \\
\hline & & .18 & - & - & - & 6.11 & - & $<.001$ \\
\hline
\end{tabular}

learning climate than at least two of the other three groups (self-fulfilling, low affective), and scored significantly lower on five of the seven dimensions of learning climate (Management Relations and Style, Autonomy and Responsibility, Team Style, Opportunities to Develop, Guidelines on How to Do the Job). Individuals defined by a selfdestructive self-report express a high level of negative affect and a low level of positive affect; this predisposition may 'color' these individuals' appraisals and interpretations of the surrounding environment, in particular under conditions of alternative environments incorporated in the learning climate dimensions. Taken together, the different expressions of work climate as reported by the affective profiles imply that affectivity (positive or negative) induced different inferences from individuals with regard to how they experienced the various aspects of the work climate.
The four affective profiles varied also with regard to the four motivational dimensions (i.e., intrinsic motivation, identified and external regulation, amotivation). High levels of expressed positive affect were associated with the more effective, self-determining types of motivation; the self-fulfilling and high affective groups both scored high in positive affect, and evidenced higher levels of intrinsic motivation and identified regulation than the low affective and self-destructive groups. Moreover, the self-fulfilling group scored significantly lower on amotivation than any of the other three groups. The self-destructive group scored significantly higher than the self-fulfilling group on external regulation, which implies a coping style that is connected with activities to avoid punishment or gain rewards (Deci \& Ryan, 1985). The present findings, pertaining to the relationship between affect and motivation in a specific occupational group (i.e., police personnel), are in accordance with previous observations (Archer et al., 
2008a). These findings may be far-reaching in their implications for how work climates in law enforcement ought to be organized: (1) a continual learning environment seems more than important, but a necessity, not least because this may offer the only avenue for individuals expressing less advantageous affectivity and motivation to develop their occupational horizons, and (2) a dynamic, learning process-oriented work climate implies the development of such attributes as resilience, locomotor self-regulation, and character, all of which contribute to the basic necessity of an individual's empowerment.

Finally, the results of regression analysis indicated that motivation may be predicted from dimensions of the learning climate. For the self-fulfilling group, intrinsic motivation and identified regulation were predicted by dimensions of the learning climate whereby Team Style and Opportunities to Develop predicted both intrinsic motivation and identified regulation, whereas Autonomy and Responsibility counterpredicted identified regulation. Although this specific finding might be perceived as counterintuitive, it actually is in line with the conceptualization of identified regulation as part of external motivation that is an "internalized" engagement, which is not self-determined yet, but is a starting point for the individual to make the reasons for her/his activity internalized (Barkoukis et al., 2008). Hence, at least for self-fulfilling individuals, high levels of Autonomy seem to go beyond doing things for one's own good (i.e., identified regulation), instead they might just do it for the activity itself or because they just want to do it. For the high affective group, intrinsic motivation was predicted by Autonomy and Responsibility, whereas Contentedness was counter-predictive for identified regulation. For the self-destructive group, intrinsic motivation was predicted by Team Style and counter-predicted by Contentedness, whereas Opportunities to Develop predicted identified regulation and counter-predicted amotivation. For both high affective and self-destructive groups, Autonomy and Responsibility counter-predicted amotivation. In other words, for high NA profiles, amotivation seems to be attenuated by high levels of Autonomy, while Contentedness among these profiles seems to be associated with low 'inner-motivation'. Lastly, for the low affective group, Opportunities to Develop predicted intrinsic motivation, and Clear Guidelines predicted identified regulation and external regulation, which was predicted also by Contentedness; Management and Opportunities to Develop counter-predicted external regulation.

In summary, Opportunities to Develop predicted different levels of self-determining motivation in three of the four affective profiles (self-fulfilling, low affective, self-destructive). This attribute is linked closely to "ability-to-learn"; both attributes are associated with the capacity of organizations/ individuals to adapt to the demands of a changing environment (Mikkelsen \& Grönhaug, 1999), thereby modulating the performance of organizations/individuals (Moss-Kanter, 1983). Opportunities to Develop appears to facilitate selfdetermining motivation as well as reducing the externally determined external regulation and amotivation. Nevertheless, high affective and self-destructive individuals, distinguished by high NA, expressed a greater need for control, a key element of the autonomy and responsibility dimension. Achievement of control in the work situation offers a buffer against environmental stress (Mikkelsen et al., 1998). Both these affective profiles present levels of stress and anxiety (Archer et al., 2007, 2008a, Palomo et al., 2008), both of which are associated with seeking control (Moriguchi \& Komaki, 2013). Opportunities to Develop provide a strategy to facilitate selfdetermining motivation concomitant with the reduction of the loss of motivation (i.e., amotivation). The results are summarized in Figure 1.

The four affective profiles expressed different types of perception of the work climate in their self-reports; thus, it was observed that the extent of self-determining motivation (on a decremental spectrum from intrinsic motivation to identified regulation to external regulation to amotivation) was either associated with (predicted by) or was dissociated from (counter-predicted by) the different factors among the learning climate.

Two specific aspects of the regression analyses should be addressed. First, why does Team Style predict intrinsic motivation for the self-fulfilling and self-destructive profiles? These two profiles represent 'opposites' with the former expressing high PA and low NA while the latter express low PA and high NA. It is possible that Team Style offers an important and necessary notion for each, but for the 'opposite' reasons. For self-fulfilling individuals, Team Style may offer a necessary component for the fulfillment of cooperative enterprises for which their personal attributes are well-suited. Conversely, for self-destructive individuals, there may exist an awareness that their personal attributes have failed to achieve fulfillment in the past, and Team Style may offer an avenue to reverse those unsuccessful past enterprises. Indeed, one of the aspects in which these two profiles differ is in the way they pursue positive emotions and life satisfaction-self-fulfillers expressing, more often than self-destructive individuals, strategies involving communal values such as cooperativeness and social affiliation (e.g., Schütz et al., 2013). In other words, being at the opposite end of the self-fulfilling profile, the intrinsic motivation of individuals with a self-destructive profile may arise from the similar work climate conditions: a work place in which cooperative values are expressed. Conversely, the intrinsic motivation of individuals with a selffulfilling profile may falter as a consequence of an uncooperative work climate.

The second question needing further explanation is: Why did Opportunities to Develop predict identified regulation for both self-fulfilling and self-destructive profiles? Identified 
Fig. 1 Summary of the results, showing differences in perception and self-report of the seven facets of the learning climate and in the four motivation dimensions between affective profiles. The figure also summarizes which facets of the learning climate that may predict self-determining motivational dimensions among the four affective profiles

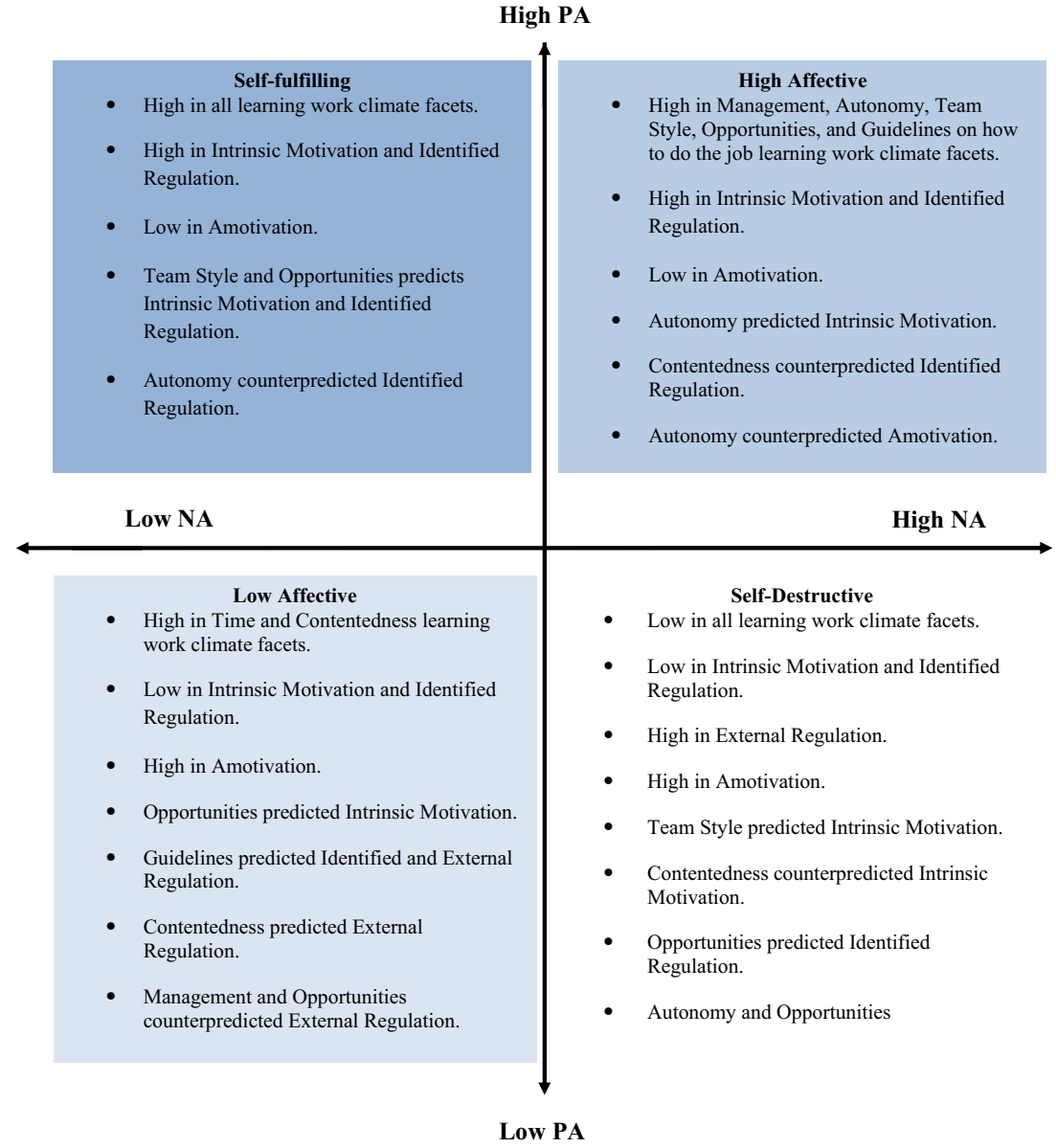

regulation, although "internalized", implies a lower level of self-determination to intrinsic motivation but nevertheless offers a starting point for the individuals to internalize the reasons for an ongoing activity. In this respect, over a continuum of self-determination, identified regulation is more closely linked to intrinsic motivation than external regulation and amotivation. Other studies show that these two profiles differ in specific aspects of their psychological well-being, such as personal growth and purpose in life (Garcia, Nima, \& Kjell, 2014). Opportunities to Develop overlap with these specific constructs of psychological well-being. It is possible that, similar to the reasoning regarding the relationship between intrinsic motivation and Team Style, selffulfilling individuals perceive Opportunities to Develop as a 'natural progression' for their attributes, whereas self-destructive individuals perceive that Opportunities to Develop also offers an avenue to reverse unsuccessful past enterprises. In other words, when individuals with a self-destructive or a self-fulfilling profile perceive the work climate as providing feasible ways of learning new jobs/tasks (i.e., high in Opportunities to Develop), the motivation for them to do their work starts to become more internalized.

\section{Limitations}

Even though the response rate in four of the five police districts was between 65 and 85 percent, the response rate in one of the districts was around 17 percent. In this particular case, there may exist skewedness in the responses collected due to the particular police district under observation. Nevertheless, the over-all response rate was well over 50 percent, which is acceptable for the purpose of the present study.

The split method used in the present study to create the affective profiles was originally validated in Archer and colleagues' work (e.g., Archer et al., 2008; Norlander et al., 2002, 2005a,b). However, other researchers (MacDonald \& KormiNouri, 2013) have applied k-means cluster analysis to create the affective profiles. This type of analysis could be suggested as more useful, compared to the split method used here, because it is often used for person-oriented analyses (see Bergman, Magnusson, \& El-Khouri, 2003). Nevertheless, not only have the four profiles relied upon in the present study been replicated using the k-means cluster analysis (MacDonald \& Kormi-Nouri, 2013; Garcia, MacDonald \& Archer, 2014), but the cut-offs for the affectivity dimensions are not significantly different between the methods (Garcia, MacDonald \& Archer, 2014). 
Finally, this study is based on self-reported cross-sectional data that imply the absence of any explicit external manipulations Given this, it is plausible to raise the question whether affectivity can actually be used as the variable predicting perceptions of the work climate. If affectivity is measured as a state, then it could be expected to be influenced by the work climate instead. However, moods and affective states have been shown to predict the way we perceive our environment (Fredrickson, 1998), and affectivity as a trait does influence our perception of the world around us (Cloninger \& Garcia, in press). At the same time, trait affectivity seems to be influenced by character traits such as self-directedness (Cloninger \& Garcia, in press). Accordingly, further experimental studies may clarify the debate regarding the direction of causation between affectivity and perceptions of the work climate.

\section{Implications}

The results indicated that an enhanced learning climate may induce positive effects on individuals' self-determining motivation in different ways, depending on their level of affectivity. These results suggest that, at a general level, a wellplanned learning-oriented organizational climate might lead to high levels of motivation and low levels of amotivation, but that the particular personal attributes of each employee (e.g., affective profile) remain an important moderator of the learning climate factors that influence specific motivation dimensions. Managers in law enforcement agencies may benefit from these observations in different ways. For instance, individuals working within their sections will vary according to the extent to which they express positive and negative emotions on a daily basis. Assuming that a dedicated manager will have a clear understanding of the affectivity profiles of her/his personnel, the present findings suggest that personnel expressing self-fulfilling/self-destructive tendencies may benefit from a more cooperative learning climate (i.e., Team Style), whereas those with high affective tendencies may benefit from a self-directed learning climate (i.e., Autonomy and Responsibility).

Furthermore, among high affective profiles, the learning climate attribute of Contentedness, which is a measure of satisfaction with the work place at a general level, was related to low levels of identified regulation. Identified regulation is a construct linked to intrinsic motivation, but that remains less self-determining. In other words, at least for the high affective profile, work place satisfaction appears to lead to a less advantageous motivation form based on doing work tasks because it is convenient to the individual. In contrast, for the low affective profile, Contentedness was related to high levels of external regulation, which provides a construct of extrinsic motivation that is even more disadvantageous. Managers working in policing should understand that, although being generally satisfied with work (i.e., high in Contentedness) is a "good thing", at least among police officers with a low affective profile, this might lead officers to be motivated to do tasks in order to gain rewards or to avoid punishment. This specific finding is in line with the definition of the low affective profile as low in "active problem solving" (Garcia et al., 2010), implying why factors controlled by others, such as management, and development opportunities that are outlined by the organization, influence their 'inner-motivation'. Indeed, explicit guidelines on how to conduct their work predicted identified regulation among police officers with a low affective profile, with identified regulation being a step toward intrinsic motivation.

For the self-destructive profile, Contentedness was related to absence of intrinsic motivation. Here, colleague-support (i.e., Team Style) was the learning climate attribute that was related to their expression of intrinsic motivation. This is in line with the definition of self-destructives as having a "depressive reaction pattern" (Garcia et al., 2013), which explains why comfort and support from others provided 'inner-motivation'. Both these profiles, low affective and self-destructive, are linked to depressiveness, anxiety, low energy, low internal locus of control, unhappiness, low levels of psychological well-being, and low values of agency and relatedness (see Garcia et al., 2013; Rapp Ricciardi, Åkerman, Eerikäinen, Ambjörnsson, Andersson Arntén et al., 2014; Schütz et al., 2013) and learned helplessness (Levine \& Ursin, 1991). Accordingly, high scores in Contentedness, implying a work place in which colleagues get along well and where people are open to try new ways of doing things, may in reality reflect resignation with different outcomes as a function of affective profile. In other words, while resignation may lead to low inner-motivation, learned helplessness, and depressiveness in self-destructive individuals, it may also be expressed in low affective individuals by poor active problem solving. It is possible that under these conditions the high levels of "Contentedness" expressed by these profiles implied a form of cognitive dissonance that the low affective and self-destructive profiles had adopted in order to function, albeit less than ideally, within their work climate (Garety \& Freeman, 1999).

Acknowledgements The development of this article was supported by The Bliwa Stiftelsen and AFA Insurance.

Open Access This article is distributed under the terms of the Creative Commons Attribution License which permits any use, distribution, and reproduction in any medium, provided the original author(s) and the source are credited.

\section{References}

Andersson Arntén, A-C. (2009). Affect, coping and health: Effects of partner relationship and work stress. PhD Thesis, University of Gothenburg, Gothenburg. 
Andersson Arntén A-C, Jansson B, Archer T (2008) Influence of affective personality type and gender upon coping behavior, mood, and stress. Individual Differences Research 6:39-168

Archer T (2014) Health Benefits of Physical Exercise for Children and Adolescents. Journal of Novel Physiotherapies 4:203. doi:10.4172/ 2165-7025.1000203

Archer T, Adolfsson B, Karlsson E (2008a) Affective personality as cognitive-emotional presymptom profiles regulatory for selfreported health predispositions. Neurotoxicity Research 14:21-44

Archer T, Adrianson L, Plancak A, Karlsson E (2007) Influence of affective personality on cognitive-mediated emotional processing: Need for empowerment. European Journal of Psychiatry 21:248-262

Archer T, Kostrzewa RM, Beninger RJ, Palomo T (2008b) Cognitive symptoms facilitatory for diagnoses in neuropsychiatric disorders: Executive functions and locus of control. Neurotoxicity Research 14(2-3):205-25. doi:10.1007/BF03033811

Atkinson JW (1964) Introduction to Motivation. Van Nostrand, Princeton, NJ

Barkoukis V, Tsorbatzoudis H, Grouios G, Sideridis G (2008) The assessment of intrinsic and extrinsic motivation and amotivation: Validity and reliability of the Greek version of the academic motivation scale. Assessment in Education: Principles, Policy \& Practice 15:39-55

Bartram D, Foster J, Lindley PA, Brown AJ, Nixon S (1993) Learning Climate Questionnaire (LCQ): Background and Technical Information. Employment Service and Newland Park Associates Limited, Oxford, 1993

Bergman, L. R., Magnusson, D., \& El-Khouri, B. M. (2003). Studying individual development in an interindividual context: A personoriented approach. Vol. 4 in the series Paths through life (D. Magnusson, Ed.). Mahwah, NJ: Erlbaum.

Bood S-Å, Archer T, Norlander T (2004) Affective personality in relation to general personality, self-reported stress, coping and optimism. Individual Differences Research 2:26-37

Boudrias J-S, Brunet L, Morin AJS, Savoie A, Plunier P, Cacciatore G (2010) Empowering employees: The moderating role of perceived organizational climate and justice. Canadian Journal of Behavioral Science 42:201-211. doi:10.1037/a0020465

Campbell JP, Pritchard RD (1976) Motivation theory in industrial and organizational psychology. In: Dunnette MD (ed) Handbook of Industrial and Organizational Psychology. Rand McNally, Chicago, pp 63-130

Cloninger CR (2004) Feeling Good: The Science of Well-being. Oxford University Press, New York

Cloninger CR (2006) Fostering spirituality and well-being in clinical practice. Psychological Annals 36:1-6

Cloninger CR, Garcia D (in press). The Heritability and Development of Positive Affect and Emotionality. In M. Pluess (Ed.), Genetics of Psychological Well-Being - The Role of Heritability and Genetics in Positive Psychology. New York: Oxford University Press

Deci EL, Ryan RM (1985) Intrinsic Motivation and Self-determination in Human Behavior. Plenum, New York

Du Preez E, Cassimjee N, Ghazinour M, Lauritz LE, Richter J (2009) Personality of South African police trainees. Psychological Reports 105:539-53

Du Preez E, Cassimjee N, Lauritz LE, Ghazinour M, Richter J (2011) Personality and mental health: An investigation of South African police trainees. Psychological Reports 108:301-16

Fredrickson BL (1998) What good are positive emotions? Review of General Psychology 2:300-319

Fredrickson BL (2006) The broaden-and-build theory of positive emotions. In: Csikszentmihalyi M, Csikszentmihalyi IS (eds) A Life Worth Living: Contributions to Positive Psychology. Oxford University Press, New York, pp 85-103

Garbarino, S., Cuomo, G., Chiorri, C., \& Magnavita, N. (2013a). Association of work-related stress with mental health problems in a special police force unit. BMJ Open. 19;3(7). doi:10.1136/ bmjopen-2013-002791.

Garbarino, S., Chiorri, C., \& Magnavita, N. (2013b) Personality traits of the five-factor model are associated with work-related stress in special force police officers. International Archives of Occupational and Environmental Health, 6.

Garcia, D. (2011) Adolescents' happiness: The role of the affective temperament model on memory and apprehension of events, subjective well-being, and psychological well-being. Ph.D. Thesis, University of Gothenburg, Gothenburg.

Garcia D (2012) The affective temperaments: Differences between adolescents in the big five model and Cloninger's psychobiological model of personality. Journal of Happiness Studies 13:999-1017. doi:10.1007/s10902-011-9303-5

Garcia D, Archer T (2012) When reaching our potential predicts low values: A longitudinal study about performance and organizational values at call centres. Journal of Service Science and Management 5: 313-317

Garcia D, Archer T (2014) Positive affect and age as predictors of exercise compliance. PeerJ 2(e):694. doi:10.7717/pj.694

Garcia D, Ghiabi B, Moradi S, Siddiqui A, Archer T (2013) The happy personality: A tale of two philosophies. In: Morris EF, Jackson M-A (eds) Psychology of Personality. Nova Science Publishers, New York, pp 41-59

Garcia D, MacDonald S, Archer T (2014). Two different approaches to the affective profiles model: Median split and cluster analysis. Unpublished Manuscript.

Garcia D, Nima AA, Kjell ONE (2014) The affective profiles, psychological well-being, and harmony: environmental mastery and selfacceptance predict the sense of a harmonious life. PeerJ 2:e259. doi: $10.7717 /$ peerj.259

Garcia D, Rapp Ricciardi M, Archer T (2015) The productive and happy agent: performance, and positive emotions at call centers. International Journal of Happiness and Development 2:84-90

Garcia D, Rosenberg P, Erlandsson A, Siddiqui A (2010) On lions and adolescents: Affective temperaments and the influence of negative stimuli on memory. Journal of Happiness Studies 11:477-495. doi: 10.1007/s10902-009-9153-6

Garety PA, Freeman D (1999) Cognitive approaches to delusions: a critical review of theories and evidence. British Journal of Clinical Psychology 38:113-54

Guay F, Vallerand RJ, Blanchard C (2000) On the assessment of Situational Intrinsic and Extrinsic Motivation: the Situational Motivation Scale (SIMS). Motivation and Emotion 24:175-213

Higgins ET (1997) Beyond pleasure and pain. American Psychologist 52: $1280-1300$

Karlsson E, Archer T (2007) Relationship between personality characteristics and affect: gender and affective personality. Individual Differences Research 5:44-58

Katzell RA, Thompson DE (1990) Work motivation, theory and practice. American Psychologist 45:144-153

Kunst MJJ (2011) Affective personality type, post-traumatic stress disorder symptom severity and post-traumatic growth in victims of violence. Stress and Health 27:42-51

Levine S, Ursin H (1991) What is stress? In: Brown MR, Koob GF, Rivier C (eds) Stress. Neurobiology and Neuroendocrinology. Marcel Decker, Inc, New York, pp 3-21

Lindahl M, Archer T (2013) Depressive expression and anti-depressive protection in adolescence: Stress, positive affect, motivation and self-efficacy. Psychology 4:495-505

MacDonald S, Korim-Nouri R (2013) The affective personality, sleep, andautobiographical memories. Journal of Positive Psychology 8: 305-313

Mikkelsen A, Grönhaug K (1999) Measuring organizational learning climate: A cross-national replication and instrument validation study 
among public sector employees. Review of Public Personnel Administration 19(31):31-44

Mikkelsen A, Saksvik PØ, Ursin H (1998) Job stress and organizational learning climate. International Journal of Stress Management 5:197209. doi:10.1023/A:1022965727976

Moriguchi, Y. \& Komaki, G. (2013). Neuroimaging studies of alexithymia: physical, affective, and social perspectives. BioPsychoSocial Medicine, 28, 7(1)8. doi: 10.1186/1751-0759-7-8.

Moss-Kanter R (1983) The Change Masters: Innovation for Productivity in the American Corporation. Simson \& Schuster, New York

Neal A, West MA, Patterson MG (2005) Do organizational climate and competitive strategy moderate the relationship between human resource management and productivity? Journal of Management 31: 492-512. doi:10.1177/0149206304272188

Norlander T, Bood S- $\AA$, Archer T (2002) Performance during stress: Affective personality age, and regularity of physical exercise. Social Behavior and Personality 30:495-508

Norlander T, Johansson $\AA$, Bood S- $\AA$ (2005a) The affective personality: Its relation to quality of sleep, well-being and stress. Social Behavior and Personality 33:709-722

Norlander T, von Schedvin H, Archer T (2005b) Thriving as a function of affective personality: Relation to personality factors, coping strategies and stress. Anxiety, Stress, and Coping 18:105-116

Palomo T, Beninger RJ, Kostrzewa RM, Archer T (2008) Focusing on symtoms rather than diagnoses in brain dysfunction: Conscious and nonconscious expression in impulsiveness and decision making. Neurotoxicity Research 14:1-20

Rapp Ricciardi M, Åkerman J, Eerikäinen P, Ambjörnsson A, Andersson Arntén A-C, Archer T, Garcia D (2014) Understanding Group and Leader (UGL) trainers' personality characteristics and affective profiles. Frontiers in Psychology 5:1191. doi:10.3389/fpsyg.2014. 01191

Ryan RM, Deci EL (2000a) Intrinsic and extrinsic motivations: Classic definitions and new directions. Contemporary Educational Psychology 25:54-67

Ryan RM, Deci EL (2000b) Self-determination theory and the facilitation of intrinsic motivation, social development, and well-being. American Psychologist 55:68-78
Shi T-H, Fan X (2008) Comparing response rates from web and mail surveys: A meta-analysis. Field Methods 20:249-271. doi:10. 1177/1525822X08317085

Schütz E, Sailer U, Nima A, Rosenberg P, Andersson-Arntén A-C, Archer T, Garcia D (2013) The affective profiles in the USA: Happiness, depression, life satisfaction, and happiness-increasing strategies. PeerJ 1:e 156. doi:10.7717/peerj.156

Steers RM, Mowday RT, Shapiro DL (2004) The future of work motivation theory. Academy of management Review 29:379-387

Tabachnick BG, Fidell LS (2007) Using Multivariate Statistics, 5th edn. Pearson Education, Inc., Boston

Tellegen A (1985) Structures of mood and personality and their relevance to assessing anxiety, with an emphasis on self-report. In: Tuma AH, Maser JD (eds) Anxiety and the Anxiety disorders. Erlbaum, Hilssdale, NJ, pp 681-706

Tellegen A (1993) Folk concepts and psychological concepts of personality and personality disorder. Psychological Inquiry 4: $122-130$

Tugade MM, Fredrickson BL (2004) Resilient individuals use positive emotions to bounce back from negative emotional arousal. Journal of Personality and Social Psychology 86:320-333

Vroom VH (1964) Work and Motivation. Wiley, New York

Watson D, Clark LA (1994) The PANAS-X: Manual for the Positive and Negative Affect Schedule-Expanded Form. University of Iowa Press, Boise

Watson D, Clark LA, Tellegen A (1988) Development and validation of brief measures of positive and negative affect: The PANAS scale. Journal of Personality and Social Psychology 54:1063-1070

Watson D, Tellegen A (1985) Toward a consensual structure of mood. Psychological Bulletin 98:219-235

Weman-Josefsson, K.A. (2014). Exploring motivational mechanisms in exercise behavior. Applying self-determination theory in personcentered approach. (unpublished Master's dissertation) University of Gothenburg, Gothenburg, Sweden.

Zhao J, He N, Lovrich N (2002) Predicting five dimensions of police officer stress: Looking more deeply into organizational settings for sources of police stress. Police Quarterly 5:43-62 